\title{
CORR $^{\circledR}$ ORS Richard A. Brand Award for Outstanding Orthopaedic Research: Engineering Flexor Tendon Repair With Lubricant, Cells, and Cytokines in a Canine Model
}

\author{
Chunfeng Zhao MD, Yasuhiro Ozasa MD, PhD, Ramona L. Reisdorf BS, \\ Andrew R. Thoreson MS, Gregory D. Jay MD, PhD, Kai-Nan An PhD, \\ Peter C. Amadio MD
}

Received: 27 November 2013/Accepted: 7 May 2014/Published online: 7 June 2014

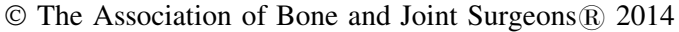

\begin{abstract}
Background Adhesions and poor healing are complications of flexor tendon repair.

Questions/purposes The purpose of this study was to investigate a tissue engineering approach to improve functional outcomes after flexor tendon repair in a canine model. Methods Flexor digitorum profundus tendons were lacerated and repaired in $60 \mathrm{dogs}$ that were followed for 10 , 21 , or 42 days. One randomly selected repair from either the second or fifth digit in one paw in each dog was treated with carbodiimide-derivatized hyaluronic acid, gelatin, and
\end{abstract}

This study was funded by a grant from the National Institutes of Health/National Institute of Arthritis and Musculoskeletal and Skin Diseases (AR44391) (PCA). One of the authors (GDJ) holds patents relating to lubricin and one of the authors (PCA) has a patent pending on a lubricant cell patch combination.

All ICMJE Conflict of Interest Forms for authors and Clinical Orthopaedics and Related Research editors and board members are on file with the publication and can be viewed on request.

Clinical Orthopaedics and Related Research neither advocates nor endorses the use of any treatment, drug, or device. Readers are encouraged to always seek additional information, including FDA-approval status, of any drug or device prior to clinical use. Each author certifies that his or her institution approved the animal protocol for this investigation and that all investigations were conducted in conformity with ethical principles of research. This work was performed in the Tendon and Soft Tissue Biology Laboratory, Mayo Clinic, Rochester, MN, USA.

C. Zhao, Y. Ozasa, R. L. Reisdorf, A. R. Thoreson, K.-N. An,

P. C. Amadio $(\square)$

Department of Orthopedic Surgery, Mayo Clinic, 200 First Street

SW, Rochester, MN 55905, USA

e-mail:pamadio@mayo.edu

G. D. Jay

Department of Emergency Medicine, Brown University, Providence, RI, USA lubricin plus autologous bone marrow stromal cells stimulated with growth and differentiation factor 5; control repair tendons were not treated. Digits were analyzed by adhesion score, work of flexion, tendon-pulley friction, failure force, and histology.

Results In the control group, 35 of 52 control tendons had adhesions, whereas 19 of 49 treated tendons had adhesions. The number of repaired tendons with adhesions in the control group was greater than the number in the treated group at all three times $(\mathrm{p}=0.005)$. The normalized work of flexion in treated tendons was $0.28( \pm 0.08), 0.29$ ( \pm 0.19$)$, and $0.32( \pm 0.22) \mathrm{N} / \mathrm{mm} /{ }^{\circ}$ at Day 10, Day 21, and Day 42 respectively, compared with the untreated tendons of $0.46( \pm 0.19)$ at Day 10 (effect size, $1.5 ; \mathrm{p}=0.01), 0.77$ $( \pm 0.49)$ at Day 21 (effect size, 1.4; p $<0.001$ ), and 1.17 $( \pm 0.82) \mathrm{N} / \mathrm{mm} /{ }^{\circ}$ at Day 42 (effect size, 1.6; p < 0.001). The friction data were comparable to the work of flexion data at all times. The repaired tendon failure force in the untreated group at 42 days was $70.2 \mathrm{~N}( \pm 8.77)$, which was greater than the treated tendons $44.7 \mathrm{~N}( \pm 8.53)$ (effect size, 1.9; $\mathrm{p}<0.001)$. Histologically, treated repairs had a smooth surface with intrinsic healing, whereas control repairs had surface adhesions and extrinsic healing.

Conclusions Our study provides evidence that tissue engineering coupled with restoration of tendon gliding can improve the quality of tendon healing in a large animal in vivo model. Clinical Relevance Tissue engineering may enhance intrinsic tendon healing and thus improve the functional outcomes of flexor tendon repair.

\section{Introduction}

Flexor tendon injuries, one of the most common and difficult-to-treat hand injuries, can cause considerable 
functional loss and economic burden [2, 20, 24]. Primary surgical repair is the accepted treatment, but hand function may be compromised by postoperative complications such as poor intrinsic healing and adhesion formation [11, 24, 30]. One study showed that surface treatment with carbodiimide-derivatized gelatin, hyaluronic acid, and lubricin (cd-HA-lubricin) effectively decreased adhesions and improved digit function after flexor tendon repair in a canine model [39]. However, this treatment also impaired tendon healing and caused another major complication: 6 weeks after repair, $35 \%$ of the tendons examined had ruptured (a significantly higher rate compared with the untreated control group) [39].

Cell-based therapy has been used to enhance tendon healing $[8,36]$. Some studies have shown that in a tissue culture model, bone marrow stromal cells increased flexor tendon healing, especially if supplemented with growth differentiation factor 5 (GDF-5). GDF-5 is a growth factor that has been shown to differentiate stem cells toward a tendon phenotype $[6,13]$. The purpose of our study was to test the hypothesis that delivery of stromal cells to the repair site through engineered cell patches could maintain the benefits of reduced adhesion from cd-HA-lubricin surface modification while maintaining tendon healing strength similar to that of repaired but otherwise untreated tendons.

\section{Materials and Methods}

\section{Study Design}

Bone marrow was harvested 3 weeks before tendon surgery, and the bone marrow stromal cell-seeded patch was fabricated immediately before surgery. At surgery, the second and fifth flexor digitorum profundus tendons from one dog forepaw were transected and repaired. Cell patches were placed between lacerated tendon ends, and then the tendon surface was treated with the lubricating mixture. At postoperative Day 5, therapy was started on the surgically treated paw which continued until the designated survival times. After euthanasia of the animal and harvesting of the tendons, the repaired tendons were evaluated mechanically, biochemically, and histologically. The study was approved by our Institutional Animal Care and Use Committee.

\section{Fabrication of the Cell Patch}

Three weeks before surgery, bone marrow was aspirated aseptically from each tibia of 60 mixed-breed dogs each approximately 1 year old and weighing approximately $20 \mathrm{~kg}$. To eliminate some confounding factors, such as gender, size of dog paw, and dog behavior, only female dogs were used in this study. The bone marrow was suspended in cell culture medium. Bone marrow stromal cells (passaged two to four times) were used to fabricate cell patches. Patches were fabricated by mixing $1 \mathrm{~mL}$ PureCol ${ }^{\circledR}$ bovine dermal collagen (Inamed Corp, Fremont, CA, USA) with $1.5 \mathrm{~mL}$ of minimum essential media (MEM), $6 \mu \mathrm{L}$ of $1.75 \mathrm{~mol} / \mathrm{L}$ $\mathrm{NaOH}$, and $0.5 \mathrm{~mL}$ of distilled $\mathrm{H}_{2} \mathrm{O}$. This $\mathrm{Col} / \mathrm{MEM}$ solution was further diluted with $3 \mathrm{~mL}$ MEM supplemented with 20\% fetal bovine serum and $2 \%$ antibiotics. A $200-\mu \mathrm{L}$ aliquot of the mixed solution was added to each well of a 48 -well dish and incubated at $37^{\circ} \mathrm{C}$ for 1 hour. A $100-\mu \mathrm{L}$ aliquot of a cell/ MEM suspension and $100 \mathrm{ng} / \mathrm{mL}$ of recombinant human GDF-5 (Abcam, Cambridge, MA, USA) then was added to each well [6]. After incubating at $37^{\circ} \mathrm{C}$ in a $5 \% \mathrm{CO}_{2}$ humidified incubator for 1 day, the bone marrow stromal cell-seeded gel was contracted in a gel droplet (approximately $1 \mathrm{~mm}$ diameter) containing $2 \times 10^{5}$ cells. This cell patch was removed from the well and used for tendon repair (Fig. 1).

\section{Surgical Procedure}

Dogs were sorted into three survival groups: 10 days, 21 days, or 42 days, with 20 dogs per group. The flexor digitorum profundus tendons of the second and fifth digits in one paw from each dog were sharply transected at the Zone II-D level [31] and repaired with a modified Pennington technique [29] using a 4-0 FiberWire ${ }^{\circledR}$ suture (Arthrex Inc, Naples, FL, USA) reinforced with a simple running suture of 6-0 Prolene ${ }^{\mathrm{TM}}$ (Ethicon Inc, Somerville, NJ, USA).

One of the two repairs was selected randomly for augmentation with cell patch transplantation and cd-HAlubricin surface treatment. After the tendons were sutured, but before tying the knot, four cell gel droplets were placed between the tendon ends with two droplets placed around two strands of suture and two droplets placed between suture strands (Fig. 2); in total, $8 \times 10^{5}$ cells were implanted. The suture loop was tied with a two-strand overhand locking knot, which was shown to have strong knot security and is suitable for tendon repair [37].

After tendon repair, the cell-augmented repaired tendon was treated with cd-HA-lubricin as previously described [39]. Briefly, cd-HA-lubricin was formulated with $1 \%$ sodium HA (95\%, molecular weight $1.5 \times 10^{6} \mathrm{Da}$; Acros Thermo Fisher Scientific, Rockford, IL, USA), $10 \%$ gelatin (Sigma, St Louis, MO, USA), 1\% 1-ethyl-3-(3-dimethylaminopropyl) carbodiimide hydrochloride (Sigma), 1\% N-hydroxysuccinimide (Pierce, Thermo Fisher Scientific, Rockford, IL USA), $0.1 \mathrm{~mol} / \mathrm{L} 2$-( $N$-morpholino) ethanesulfonic acid (MES) (pH 6.0), and $260 \mu \mathrm{g} / \mathrm{mL}$ bovine lubricin. After tendon repair, a radial neurectomy was performed through a lateral humeral incision to denervate the elbow and wrist extensors so that the 


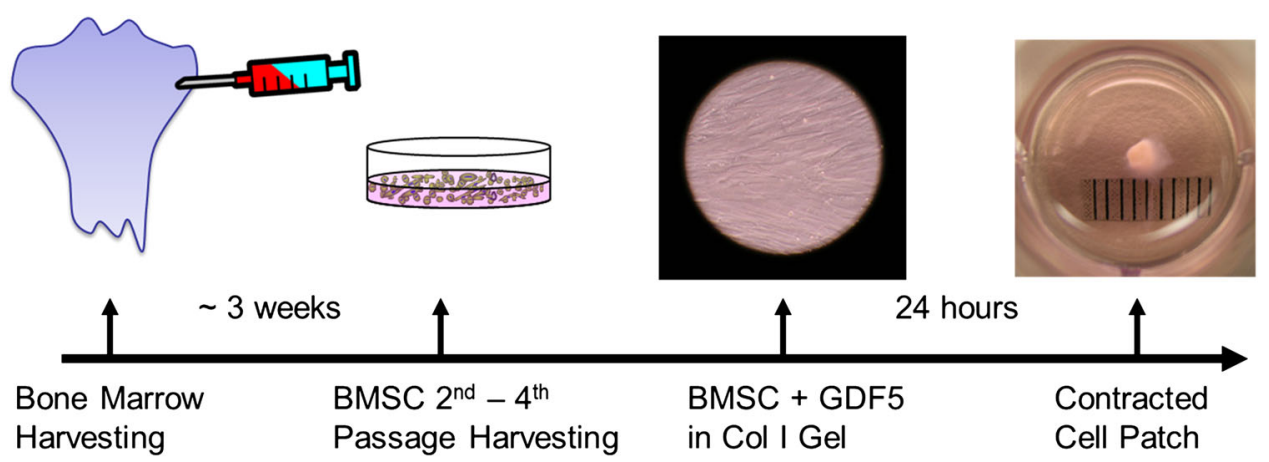

Fig. 1 A flowchart shows the timeline of patch fabrication with $2 \times 10^{5}$ cells per approximately 1-mm patch. BMSC = bone marrow stromal cell; GDF5 = growth differentiation factor 5 .

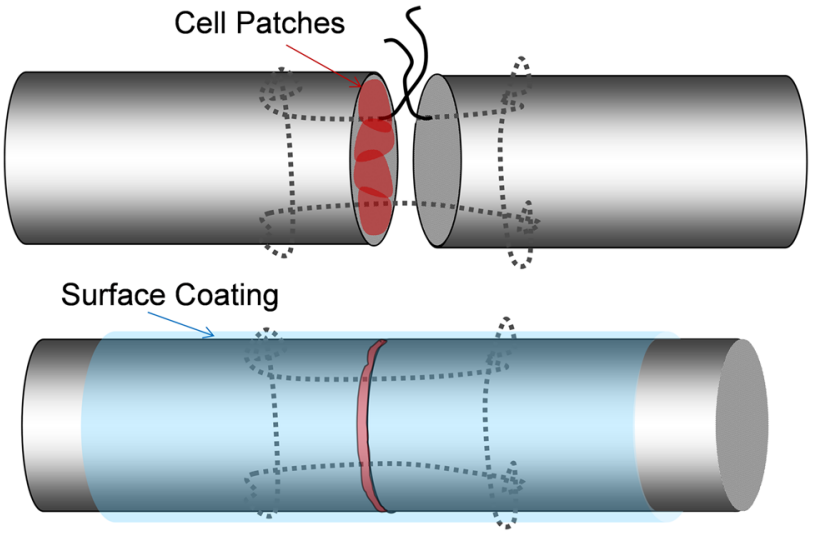

Fig. 2 The flexor tendon was repaired with a modified Pennington suture. Four patches of cells were implanted at the repair site. The tendon surface was coated with cd-HA-lubricin after repair.

dogs could not bear weight on the surgically treated limb [39]. After surgery, the surgically treated paw was maintained in front of the chest with a custom sling for 5 days; then, synergistic motion rehabilitation was performed daily until euthanasia [39].

\section{Biomechanical Evaluation}

After euthanasia, 10 digits in each group were tested for digit work of flexion normalized by digit joint motion known as normalized work of flexion using a well-established protocol [38]. For comparison, normalized work of flexion and friction also were measured in the contralateral, intact untreated digits (Fig. 3A). After work of flexion testing, digits were carefully exposed in Zone II, and adhesions were scored in four categories (from none to severe; Table 1) [12]. The unblinded evaluation was scored by two authors (RLR and CZ or YO), with the final score being a consensus of the two assessments in each region. After adhesion evaluation, the repaired tendon was isolated, and friction between the repaired tendon and proximal pulley was measured as previously described (Fig. 3B) [33]. Finally, to evaluate healing strength, the mechanical failure force and stiffness of the repaired tendon were tested by using a servohydraulic testing machine (MTS Systems, Eden Prairie, MN, USA) (Fig. 3C) [35]. Ten flexor digitorum profundus tendons from the second to fifth digits from the contralateral nonoperative paws were lacerated and repaired using the same technique and suture materials described and then immediately tested. This force to failure was considered the repair strength at Time 0 .

\section{Biochemistry}

Quantitative real-time reverse transcription-polymerase chain reaction (qPCR) was used to evaluate collagen type 1 (Col1), collagen type 3 (Col3), tenomodulin, fibronectin, and transforming growth factor-beta (TGF- $\beta$ ) expression in eight samples from each group according to established protocols [18]. Col1 and Col3 are the functional markers for tenocyte production, tenomodulin is a tenocyte-specific marker, and fibronectin and TGF- $\beta$ are the markers indicating cell activities. Briefly, a 20-mm repaired tendon segment, with the repair site in the center, was harvested and snap-frozen in liquid nitrogen and stored at $-80^{\circ} \mathrm{C}$ until RNA extraction. RNA was purified using miRNeasy Micro kit (QIAGEN, Germantown, MD, USA). RNA concentration was determined using a NanoDrop ND-1000 spectrophotometer (Thermo Scientific, Waltham, MA, USA). Total RNA was reverse-transcribed into single-stranded cDNA using the Transcriptor First Strand cDNA Synthesis Kit (Roche, Indianapolis, IN, USA). A random primer was used in the reaction. A LightCycler ${ }^{\circledR}$ FastStart DNA Master SYBR Green I kit (Roche) was used for qPCR. The target sequence was amplified simultaneously with primers (Table 2), reported in previous studies $[17,18]$, for the mRNA of interest and a constitutively expressed housekeeping gene, glyceraldehyde-3-phosphate dehydrogenase (GAPDH) [25] . 


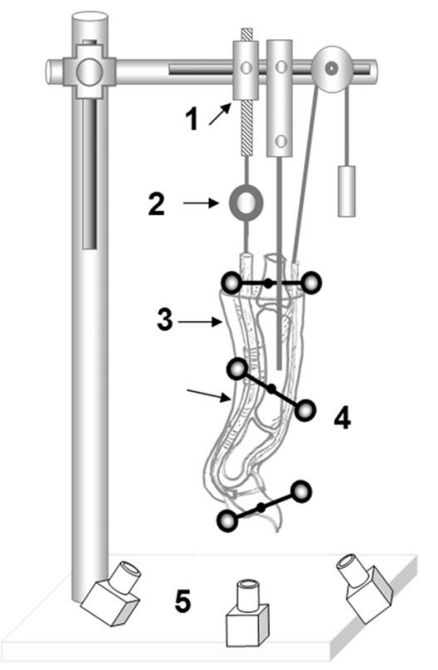

A

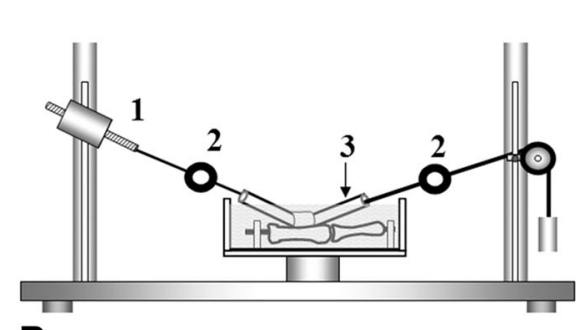

B

1. Motor with Actuator

2. Load Transducers

3. Specimen

4. Reflective Sensors

\section{Motion Camcorders}

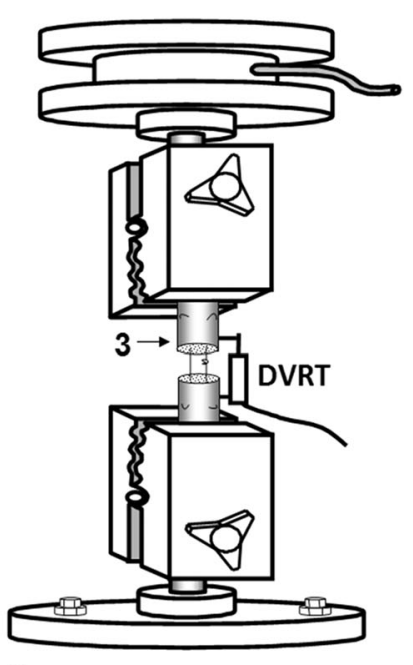

C

Fig. 3A-C Drawings of the testing apparatus used to evaluate work of flexion for (A) digit function, (B) repaired tendon gliding resistance, and (C) repaired tendon mechanical strength are shown. DVRT $=$ differential variable reluctance transducer.

Table 1. Adhesion score

\begin{tabular}{ll}
\hline Categories & Adhesion measures \\
\hline None & No adhesions \\
Mild & Less than $2 \mathrm{~mm}$ between tendon and \\
& surrounding tissue, easy to separate \\
Moderate & $3-4 \mathrm{~mm}$ can separate \\
Severe & More than $5 \mathrm{~mm}$, difficult to separate \\
\hline
\end{tabular}

Cell Tracking and Histology

Two repaired tendons from each group were used to track the implanted bone marrow stromal cells on postoperative Days 10, 21, and 42 to assess cell viability and distinguish bone marrow stromal cells from the host tenocytes, based on a previous report [36]. Briefly, bone marrow stromal cells were labeled with $\mathrm{PKH} 26$ red fluorescent cell linker (Sigma) before seeding in the gel patch. Labeled cell patches then were transplanted into repaired tendon ends as described previously. After euthanasia of the dogs, tendons were harvested immediately, observed with a confocal microscope (LSM310; Zeiss, Oberkochen, Germany), fixed with $10 \%$ formalin, and embedded in paraffin. Tendon sections ( $7 \mu \mathrm{m}$ thick) were cut and stained with hematoxylin and eosin. These sections were qualitatively evaluated by light microscopy.

\section{Statistical Analysis}

The tendon rupture rate and adhesion score were analyzed with Fisher's exact test. Since the mechanical testing and gene expression data were normally distributed, the data were reported as mean (SD); treated and untreated groups were compared with a paired t-test at each time because different digits in one dog were being compared. One-way ANOVA was used to test differences among the three times because comparisons were made among different dogs. Probability values less than 0.05 were considered statistically significant. JMP ${ }^{\circledR}$ software (SAS Institute Inc, Cary, NC, USA) was used for data analysis.

\section{Results}

Rupture occurred in eight of 60 control tendons and 11 of 60 treated tendons. The frequency of rupture of the repair was not different between the patch-augmented and control groups at any time $(\mathrm{p}=0.62)$. The ruptured tendons were excluded from the adhesion score. In the control group, 35 of 52 control tendons had adhesions, whereas 19 of 49 treated tendons had adhesions. The number of repaired tendons with adhesions in the control group was greater than that in the treated group at all three times $(\mathrm{p}=0.005)$ (Table 3).

The normalized work of flexion in treated tendons was less than in untreated tendons. In treated tendons, it was $0.28( \pm 0.08) \mathrm{N} / \mathrm{mm} /{ }^{\circ}, 0.29( \pm 0.19) \mathrm{N} / \mathrm{mm} /{ }^{\circ}$, and 0.32 $( \pm 0.22) \mathrm{N} / \mathrm{mm} /{ }^{\circ}$ at Day 10 , Day 21 , and Day 42 respectively compared with the untreated tendons of 0.46 $( \pm 0.19) \mathrm{N} / \mathrm{mm} /{ }^{\circ}$ at Day 10 (effect size, $1.5 ; \mathrm{p}=0.01$ ), $0.77( \pm 0.49) \mathrm{N} / \mathrm{mm} /{ }^{\circ}$ at Day 21 (effect size, 1.4; $\mathrm{p}<0.001$ ), and $1.17( \pm 0.82) \mathrm{N} / \mathrm{mm} /{ }^{\circ}$ at Day 42 (effect size, 1.6; $\mathrm{p}<0.001)($ Fig $4 \mathrm{~A})$. The friction of the treated 
Table 2. Sequences of polymerase chain reaction primers and the length of amplicons

\begin{tabular}{|c|c|c|c|}
\hline Gene & Accession number & Primers $\left(5^{\prime}-3^{\prime}\right)$ & Size (bp) \\
\hline \multirow[t]{2}{*}{ COL1A1 } & \multirow[t]{2}{*}{ AF153062 } & TGGTTCTCCTGGCAAAGAT & \multirow[t]{2}{*}{232} \\
\hline & & ATCACCGGGTTCACCTTTA & \\
\hline \multirow[t]{2}{*}{ COL3A1 } & \multirow[t]{2}{*}{ XM_535997 } & ACAGCAGCAAGCTATTGAT & \multirow[t]{2}{*}{156} \\
\hline & & GGACAGTCTAATTCTTGTTCGT & \\
\hline \multirow[t]{2}{*}{ Fibronectin } & \multirow[t]{2}{*}{ CFU52106 } & GATGACTCGTGCTTCGAC & \multirow[t]{2}{*}{183} \\
\hline & & CTTCTCGCCAATCTTGTAGTT & \\
\hline \multirow[t]{2}{*}{ Lubricin } & \multirow[t]{2}{*}{ XM_547439 } & GGCCCGCTATCAATTACC & \multirow[t]{2}{*}{157} \\
\hline & & ACTTCATTATGGAGGAAACCTTTA & \\
\hline \multirow[t]{2}{*}{ TGF $\beta-1$} & \multirow[t]{2}{*}{ NM_001003309 } & ACCATTCATGGCATGAACC & \multirow[t]{2}{*}{174} \\
\hline & & CAGATCCTTGCGGAAGTC & \\
\hline \multirow[t]{2}{*}{ GAPDH } & \multirow[t]{2}{*}{$\mathrm{AB} 038240$} & TATGATTCTACCCACGGCAA & \multirow[t]{2}{*}{154} \\
\hline & & CAGTGGACTCCACAACATAC & \\
\hline
\end{tabular}

COL1A1 = collagen type 1 , alpha 1 ; COL3A1 = collagen type 3 , alpha 1 ; GAPDH = glyceraldehyde- 3 -phosphate dehydrogenase; TGF $\beta$ $1=$ transforming growth factor-beta 1 .

Table 3. Numbers of adhesions in control and treated groups

\begin{tabular}{|c|c|c|c|c|c|c|c|c|}
\hline \multirow[t]{2}{*}{ Adhesions } & \multicolumn{4}{|l|}{ Control } & \multicolumn{4}{|l|}{ Treated } \\
\hline & $\begin{array}{l}\text { Day } 10 \\
(\mathrm{n}=18)\end{array}$ & $\begin{array}{l}\text { Day } 21 \\
(\mathrm{n}=18)\end{array}$ & $\begin{array}{l}\text { Day } 42 \\
(\mathrm{n}=16)\end{array}$ & $\begin{array}{l}\text { Total } \\
(\mathrm{n}=52)\end{array}$ & $\begin{array}{l}\text { Day } 10 \\
(\mathrm{n}=16)\end{array}$ & $\begin{array}{l}\text { Day } 21 \\
(\mathrm{n}=17)\end{array}$ & $\begin{array}{l}\text { Day } 42 \\
(\mathrm{n}=16)\end{array}$ & $\begin{array}{l}\text { Total } \\
(\mathrm{n}=49)\end{array}$ \\
\hline None & 10 & 5 & 2 & 17 & 15 & 10 & 8 & 30 \\
\hline Mild & 7 & 2 & 1 & 10 & 1 & 2 & 3 & 8 \\
\hline Moderate & 1 & 9 & 11 & 21 & 0 & 4 & 5 & 9 \\
\hline Severe & 0 & 2 & 2 & 4 & 0 & 1 & 0 & 2 \\
\hline Total adhesions & 8 & 13 & 14 & 35 & 1 & 7 & 8 & 19 \\
\hline
\end{tabular}

Fig. 4A-B The outcomes of tendon repair were evaluated for (A) normalized work of flexion (nWOF) and (B) friction of repaired tendons. $\mathrm{a}=$ significant difference compared with treated tendon; $\mathrm{b}=$ significant difference compared with normal tendon; $\mathrm{x}=$ significant difference compared with Day 21; $y=$ significant difference compared with Day 10.

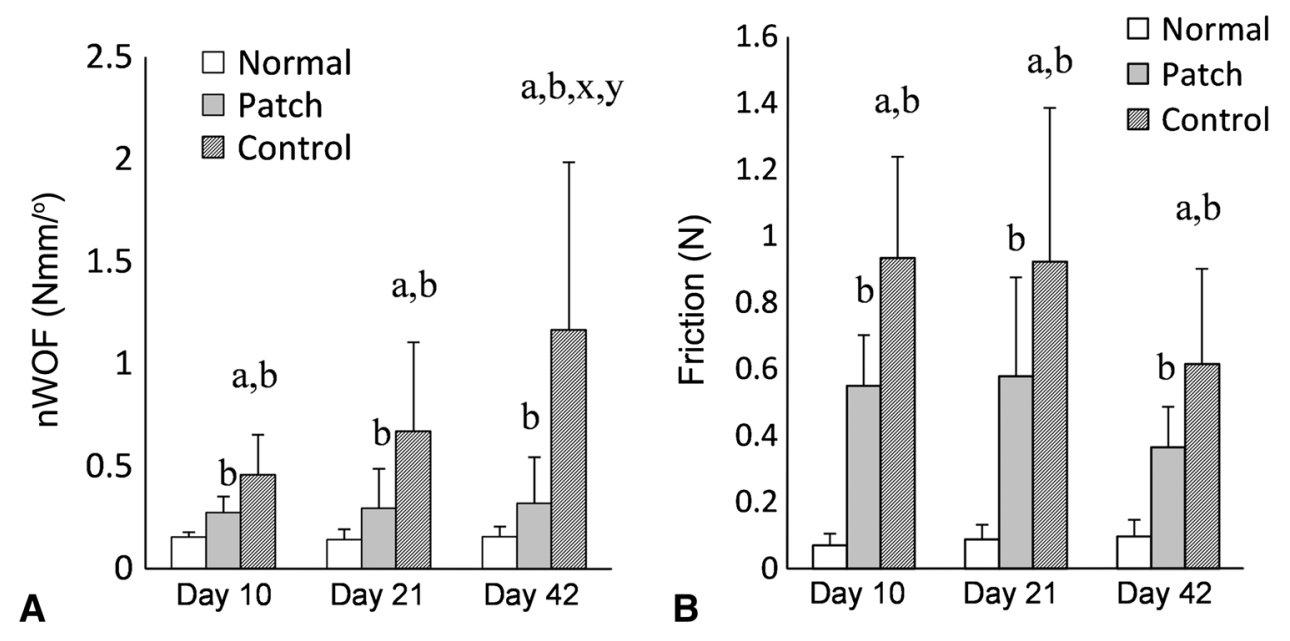

repairs was $0.55( \pm 0.15) \mathrm{N}, 0.52( \pm 0.2) \mathrm{N}$, and 0.36 $( \pm 0.12) \mathrm{N}$ at Day 10, Day 21, and Day 42 respectively which was lower than $0.93( \pm 0.3) \mathrm{N}$ at Day 10 (effect size, $1.7 ; \mathrm{p}=0.006), 0.98( \pm 0.46) \mathrm{N}$ at Day 21 (effect size, $1.4 ; \mathrm{p}=0.016)$, and $0.62( \pm 0.02) \mathrm{N}$ at Day 42 (effect size, 1.6; $\mathrm{p}=0.03$ ) in the untreated groups (Fig 4B).
The repaired tendon failure force in the untreated group at 42 days was $70.2( \pm 18.77) \mathrm{N}$, which was greater than the treated tendons $44.7( \pm 8.53) \mathrm{N}$ (effect size, 1.9; $\mathrm{p}<0.001)$. The stiffness in untreated tendons at Day 42 $(26.1 \mathrm{~N} / \mathrm{mm} \pm 13.08)$ was greater than the treated tendons at Day $42 \quad(15.62 \mathrm{~N} / \mathrm{mm} \pm 5.19$; effect size, 1.2 ; $\mathrm{p}<0.001)$ and also the repair stiffness at Time 0 


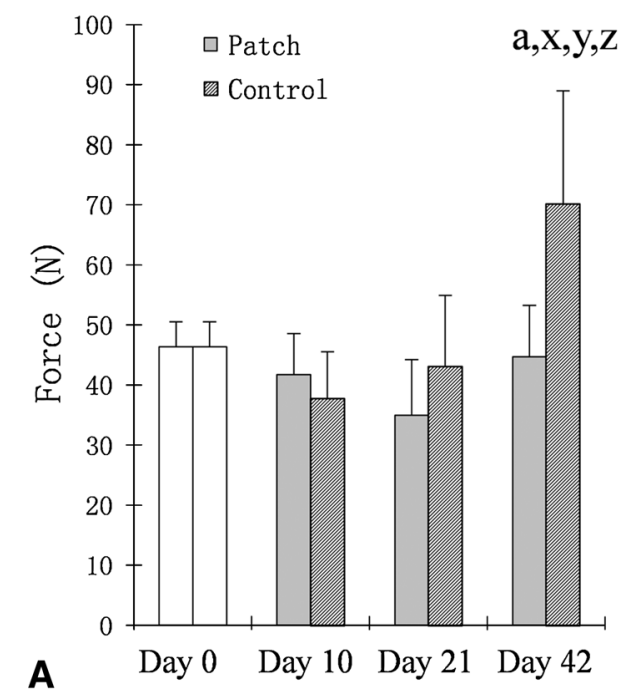

Fig. 5A-B The outcomes of tendon repair were evaluated for (A) failure strength (force) and (B) stiffness. a = significant difference compared with treated tendon; $\mathrm{x}=$ significant difference compared

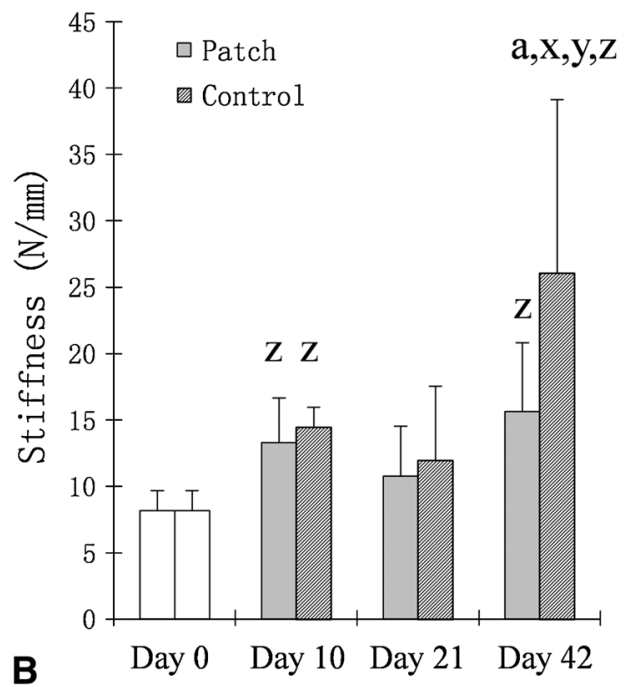

with Day $21 ; y=$ significant difference compared with Day 10; $\mathrm{z}=$ significant difference compared with Day 0 .

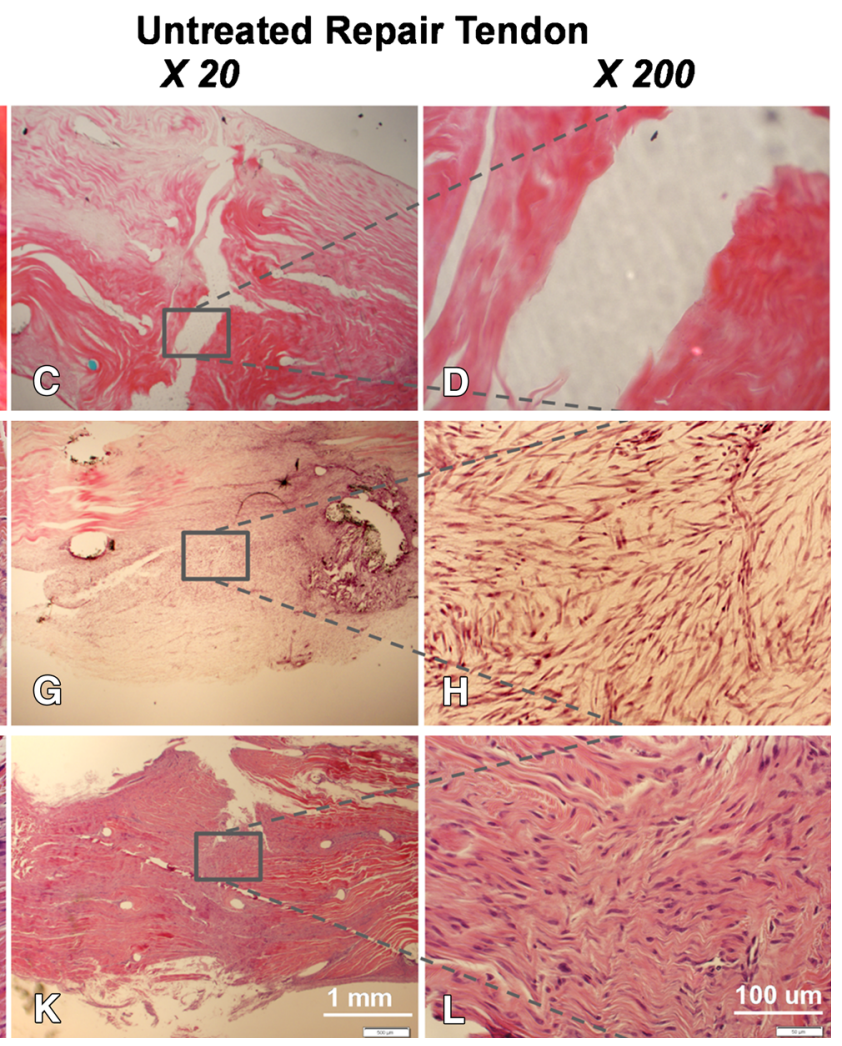

nontreated repair at $(\mathbf{G}) \times 20$ and $(\mathbf{H}) \times 200$ magnification; and at Day 42 in a treated repair at $(\mathbf{I}) \times 20$ and $(\mathbf{J}) \times 200$ magnification and a nontreated repair at $(\mathbf{K}) \times 20$ and $(\mathbf{L}) \times 200$ magnification. (Stain, Hematoxylin and eosin).

Expression of Col1, Col3, fibronectin, tenomodulin, or TGF- $\beta$ was not different between treated and untreated tendons at any time $(\mathrm{p}>0.05)$. Hematoxylin and eosin staining showed a gap between the repaired tendon ends in 

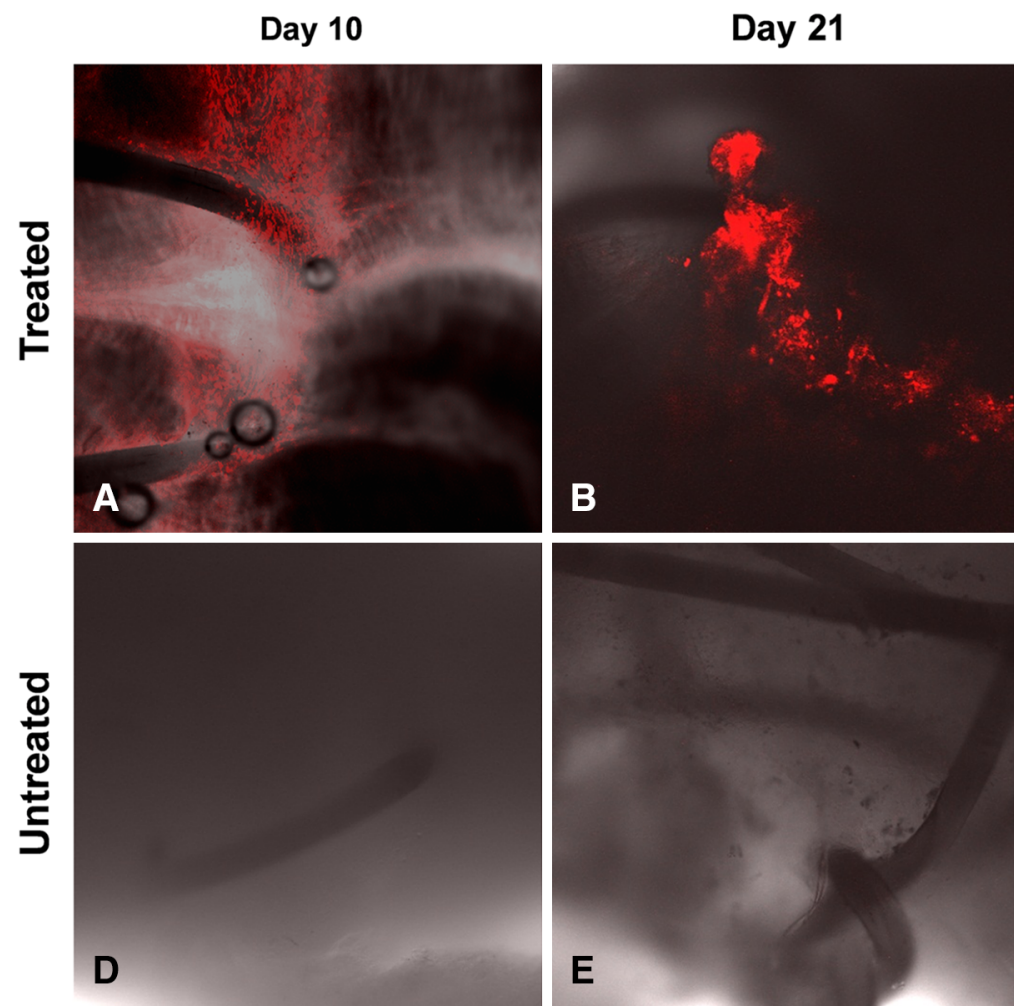

Fig. 7 Confocal micrographs show the bone marrow stromal cells tracked with PKH26. The cells were observed at the repair site of treated tendons at (A) Day 10 and (B) Day 21, but the cell population appeared to decrease at (C) Day 42 (Stain, PKH26 cell tracker;

treated and untreated tendons (Fig. 6), with a hypocellular appearance in untreated tendons (Fig. 6D) and numerous cells around the suture area in treated tendons (Fig. 6B). At Day 21, the treated tendon had a smooth surface without adhesions, and the repaired tendon ends were fully connected with numerous cells and no gapping (Fig. 6E-F). Although the repair site in untreated tendons also appeared to be healed, the tendon surface showed hypertrophic fibrous tissue (Fig. 6G-H). At Day 42, cellularity was decreased in treated and untreated repaired tendons, although treated tendons had a smoother surface compared with untreated tendons (Fig. 6I-J). Labeled transplanted cells were observed on Days 10, 21, and 42 at the repair site of the treated tendon, although cell density apparently decreased with time (Fig. 7).

\section{Discussion}

Two major complications often are encountered after flexor tendon repair: adhesion formation and repair rupture $[24,30]$. These complications are highly related to the flexor tendon's low capacity for intrinsic healing because of its hypocellular and hypovascular nature $[9$, 32]. Delayed intrinsic healing not only increases the risk original magnification, $\times 100)$. Tracked cells were not observed in the repaired tendon without treatment at (D) Day 10, (E) Day 21, and (F) Day 42.

of repair rupture, but also provokes extrinsic healing, leading to adhesion formation. Although postoperative mobilization, especially using an active motion protocol, effectively decreases adhesions, it also may promote gap formation at the repair site, which further impairs tendon healing. We therefore sought to evaluate the effects of the combination of the surface treatment with lubricating molecules to prevent adhesion formation and stem cellbased therapy to enhance tendon intrinsic healing on functional outcomes after flexor tendon repair using a canine model.

Our study has several limitations. First, we used female dogs only to minimize the confounding factors caused by sex difference. Therefore, the findings might not generalize to both genders, and future studies may evaluate the gender effect of the treatments. Second, we did not test either the cell-based therapy or surface modification alone. However, some studies have shown that bone marrow stromal cells do increase tendon healing capacity $[8,10,15]$, and others have shown that surface modification decreases tendon adhesions [14, 40]. Therefore, the purposes of our study were to investigate the effects of combining these treatments on postoperative adhesion formation and tendon healing. The surface modification procedures were not blinded because a placebo substance was not used. Third, 
the viable transplanted cells were not counted. Although qualitative images showed cell density decreasing with time, we do not know the survival rate of implanted cells. Fourth, because of difficulty with accurate measurement of the cross-sectional area of the repaired tendon with adhesions, the breaking strength values could not be normalized. Fifth, the endpoint was 42 days. Longer followup may be needed. Finally, 2 to 3 weeks are needed for the bone marrow stromal cell preparation, which limits clinical applicability for acute tendon injuries. However, delayed primary repairs are commonly performed, and a delay of as much as 3 weeks is not associated with worse results [21].

The effects of surface modification with biolubricating molecules such as hyaluronic acid and lubricin after flexor tendon repair have been investigated $[26,38]$. Taguchi et al. [27] reported an in vitro study in which surface treatment with cd-HA-lubricin decreased the gliding resistance in a repaired flexor digitorum profundus tendon and restored the smoothness of the tendon surface. Zhao et al. [38] conducted an in vivo canine study and showed that cd-HAgelatin-lubricin decreased adhesions, increased tendon gliding ability, and improved digit function. However, they also observed greater tendon rupture rates in treated tendons compared with untreated controls and the repair stiffness was less in treated repairs at all times [38]. To maintain the benefits of the lubricant treatment on adhesion formation and tendon gliding, while countering the adverse effects on healing, we added a cell-based therapy to the lubricant. Our findings suggest that cell-based therapy can improve, at least partially, the delayed healing associated with antiadhesion surface modification, as evidenced by similar rupture rates and repair stiffness in treated and untreated repaired tendons at Days 10 and 21. Notably, the reduced adhesion formation was similar when comparing lubricated repairs with or without cellular augmentation, so that the benefit of improved healing was not obtained at the expense of worse adhesions. Increased maximum failure strength of the untreated tendon at 42 days might be the result of excessive adhesion around repair site (Fig. 8). However, the crosssectional area of the repaired tendon is difficult to measure owing to irregular geometry.

Cell-based therapy has been investigated as a means to accelerate tendon healing. Embryonic stem cells, induced pluripotent stem cells, and adult mesenchymal stem cells $[4,16,34]$ have been studied for their differentiation potential, function, regenerative capacity, and side effects. Adult mesenchymal stem cells most commonly are used clinically and experimentally. Although the adult mesenchymal stem cells can be derived from bone marrow, adipose, muscle, and other tissue, the most common use in tendon healing to date is the use of bone marrow stromal cells to treat equine flexor tendon injures $[3,5,19,22,23]$.

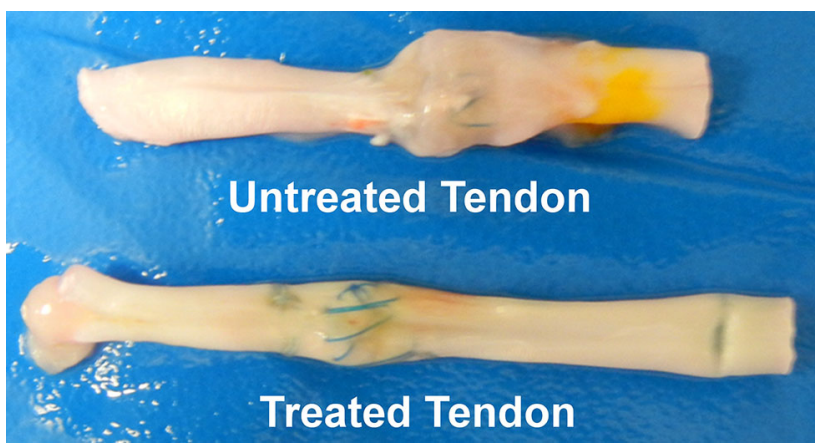

Fig. 8 The untreated repaired tendon shows adhesion formation around the repair site, thus increasing the volume of the repair. The treated repaired tendon has a smooth surface without adhesions.

Several studies have shown that bone marrow stromal cells increase repaired flexor tendon strength and stiffness in a canine ex vivo model $[6,13,36]$. Manning et al. [8] used adipose mesenchymal stem cells to treat flexor tendon lacerations using a canine in vivo model, and cells remained viable at the repair site for 9 days. However, no mechanical data such as digit function or repair strength were reported in that study. They did not find any difference in gene expression comparing treated and untreated repairs, which was similar to our findings. The lack of difference in gene expression may relate to the fact that the sample they used and the sample that we used for analysis was a segment of the tendon in which transplanted cells and local resident cells were admixed.

Several growth factors have been used to enhance cellbased therapy for tendon regeneration, including GDF-5, GDF-6, platelet-derived growth factor, and platelet-rich plasma [1, 6, 7]. Tan et al. [28] used GDF-5 to treat bone marrow stromal cells and reported that a $100-\mathrm{ng} / \mathrm{mL}$ treatment caused cells to increase collagen expression, upregulate tenogenic marker expression (including scleraxis and tenascin-C), and downregulate nontenogenic marker expression (including runt-related transcription factor 2 [Runx2] and sex-determining region Y-box 9 [Sox 9]). They concluded that GDF-5 induced bone marrow stromal cell tenogenic differentiation [28]. Hayashi et al. [6] examined tendon healing in a tissue culture model and found that GDF-5 (100 ng/mL) promoted bone marrow stromal cell production and increased tendon intrinsic healing. These studies provided a strong rationale for using $100 \mathrm{ng} / \mathrm{mL}$ GDF-5 for stimulation of bone marrow stromal cells in the current in vivo flexor tendon healing model.

Augmentation of a cd-HA-lubricin-treated tendon repair with GDF-5 stimulated bone marrow stromal cells in a collagen patch delivered to the repair site at the time of surgery improved but did not completely correct the impaired healing previously noted with use of cd-HAlubricin alone [39]. The augmentation did not appear to 
result in any additional adhesions. Considering these results, we believe that cell-based repair therapy, coupled with methods to reduce tendon surface friction, has the potential to enhance tendon intrinsic healing. However, further studies are warranted to assess the use of different cell sources, different cell doses, different carrier vehicles, and different cytokines, in various combinations, to achieve the ultimate goal of strong tendon healing without adhesions.

Acknowledgments We thank Masanori Hayashi MD, PhD and Kumar Chokalingam PhD, Department of Orthopedic Surgery, Mayo Clinic for their assistance with surgical procedures and RT-PCR analysis.

\section{References}

1. Chai W, Ni M, Rui YF, Zhang KY, Zhang Q, Xu LL, Chan KM, Li G, Wang Y. Effect of growth and differentiation factor 6 on the tenogenic differentiation of bone marrow-derived mesenchymal stem cells. Chin Med J (Engl). 2013;126:1509-1516.

2. Clayton RA, Court-Brown CM. The epidemiology of musculoskeletal tendinous and ligamentous injuries. Injury. 2008;39:1338-1344.

3. Crovace A, Lacitignola L, Rossi G, Francioso E. Histological and immunohistochemical evaluation of autologous cultured bone marrow mesenchymal stem cells and bone marrow mononucleated cells in collagenase-induced tendinitis of equine superficial digital flexor tendon. Vet Med Int. 2010;2010:250978.

4. Filomeno P, Dayan V, Tourino C. Stem cell research and clinical development in tendon repair. Muscles Ligaments Tendons J. 2012;2:204-211.

5. Godwin EE, Young NJ, Dudhia J, Beamish IC, Smith RK. Implantation of bone marrow-derived mesenchymal stem cells demonstrates improved outcome in horses with overstrain injury of the superficial digital flexor tendon. Equine Vet J. 2012;44: 25-32.

6. Hayashi M, Zhao C, AN K, Amadio P. The effects of growth and differentiation factor 5 on bone marrow stromal cell transplants in an in vitro tendon healing model. J Hand Surg Eur Vol. 2011; 36:271-279.

7. James R, Kumbar SG, Laurencin CT, Balian G, Chhabra AB. Tendon tissue engineering: adipose-derived stem cell and GDF-5 mediated regeneration using electrospun matrix systems. Biomed Mater. 2011;6:025011.

8. Manning CN, Schwartz AG, Liu W, Xie J, Havlioglu N, Sakiyama-Elbert SE, Silva MJ, Xia Y, Gelberman RH, Thomopoulos S. Controlled delivery of mesenchymal stem cells and growth factors using a nanofiber scaffold for tendon repair. Acta Biomater. 2013;9:6905-6914.

9. Manske PR, Gelberman RH, Lesker PA. Flexor tendon healing. Hand Clin. 1985;1:25-34.

10. Martinello T, Bronzini I, Perazzi A, Testoni S, De Benedictis GM, Negro A, Caporale G, Mascarello F, Iacopetti I, Patruno M. Effects of in vivo applications of peripheral blood-derived mesenchymal stromal cells (PB-MSCs) and platlet-rich plasma (PRP) on experimentally injured deep digital flexor tendons of sheep. J Orthop Res. 2013;31:306-314.

11. May EJ, Silfverskiold KL. Rate of recovery after flexor tendon repair in zone II: a prospective longitudinal study of 145 digits. Scand J Plast Reconstr Surg Hand Surg. 1993;27:89-94.
12. Moran SL, Ryan CK, Orlando GS, Pratt CE, Michalko KB. Effects of 5-fluorouracil on flexor tendon repair. J Hand Surg Am. 2000;25:242-251.

13. Morizaki Y, Zhao C, An KN, Amadio PC. The effects of plateletrich plasma on bone marrow stromal cell transplants for tendon healing in vitro. J Hand Surg Am. 2010;35:1833-1841.

14. Moro-oka T, Miura H, Mawatari T, Kawano T, Nakanishi Y, Higaki $\mathrm{H}$, Iwamoto $\mathrm{Y}$. Mixture of hyaluronic acid and phospholipid prevents adhesion formation on the injured flexor tendon in rabbits. J Orthop Res. 2000;18:835-840.

15. Muttini A, Salini V, Valbonetti L, Abate M. Stem cell therapy of tendinopathies: suggestions from veterinary medicine. Muscles Ligaments Tendons J. 2012;2:187-192.

16. Nagy K, Sung HK, Zhang P, Laflamme S, Vincent P, AghaMohammadi S, Woltjen K, Monetti C, Michael IP, Smith LC, Nagy A. Induced pluripotent stem cell lines derived from equine fibroblasts. Stem Cell Rev. 2011;7:693-702.

17. Omae H, Sun YL, An KN, Amadio PC, Zhao C. Engineered tendon with decellularized xenotendon slices and bone marrow stromal cells: an in vivo animal study. J Tissue Eng Regen Med. 2012;6:238-244.

18. Omae H, Zhao C, Sun YL, Zobitz ME, Moran SL, Amadio PC. The effect of tissue culture on suture holding strength and degradation in canine tendon. J Hand Surg Eur Vol. 2009;34:643-650.

19. Pacini S, Spinabella S, Trombi L, Fazzi R, Galimberti S, Dini F, Carlucci F, Petrini M. Suspension of bone marrow-derived undifferentiated mesenchymal stromal cells for repair of superficial digital flexor tendon in race horses. Tissue Eng. 2007; 13:2949-2955.

20. Rosberg HE, Carlsson KS, Hojgard S, Lindgren B, Lundborg G, Dahlin LB. What determines the costs of repair and rehabilitation of flexor tendon injuries in zone II? A multiple regression analysis of data from southern Sweden. J Hand Surg Eur Vol. 2003;28:106-112.

21. Schneider LH, Hunter JM, Norris TR, Nadeau PO. Delayed flexor tendon repair in no man's land. J Hand Surg Am. 1977;2:452-455.

22. Smith RK. Mesenchymal stem cell therapy for equine tendinopathy. Disabil Rehabil. 2008;30:1752-1758.

23. Smith RK, Korda M, Blunn GW, Goodship AE. Isolation and implantation of autologous equine mesenchymal stem cells from bone marrow into the superficial digital flexor tendon as a potential novel treatment. Equine Vet J. 2003;35:99-102.

24. Strickland JW. Development of flexor tendon surgery: twentyfive years of progress. J Hand Surg Am. 2000;25:214-235.

25. Sun YL, Thoreson AR, Cha SS, Zhao C, An KN, Amadio PC. Temporal response of canine flexor tendon to limb suspension. J Appl Physiol. 2010;109:1762-1768.

26. Sun YL, Yang C, Amadio PC, Zhao C, Zobitz ME, An KN. Reducing friction by chemically modifying the surface of extrasynovial tendon grafts. J Orthop Res. 2004;22:984-989.

27. Taguchi M, Sun Y, Zhao C, Zobitz M, Cha C, Jay G, An K, Amadio P. Lubricin surface modification improves tendon gliding after tendon repair in a canine model in vitro. J Orthop Res. 2009;27:257-263.

28. Tan SL, Ahmad RE, Ahmad TS, Merican AM, Abbas AA, Ng WM, Kamarul T. Effect of growth differentiation factor 5 on the proliferation and tenogenic differentiation potential of human mesenchymal stem cells in vitro. Cells Tissues Organs. 2012; 196:325-338.

29. Tanaka T, Amadio PC, Zhao C, Zobitz ME, Yang C, An KN. Gliding characteristics and gap formation for locking and grasping tendon repairs: a biomechanical study in a human cadaver model. J Hand Surg Am. 2004;29:6-14.

30. Tang JB. Clinical outcomes associated with flexor tendon repair. Hand Clin. 2005;21:199-210. 
31. Tang JB, Shi D. Subdivision of flexor tendon "no man's land" and different treatment methods in each sub-zone: a preliminary report. Chin Med J (Engl). 1992;105:60-68.

32. Tozer S, Duprez D. Tendon and ligament: development, repair and disease. Birth Defects Res C Embryo Today. 2005;75: 226-236.

33. Uchiyama S, Coert JH, Berglund L, Amadio PC, An KN. Method for the measurement of friction between tendon and pulley. J Orthop Res. 1995;13:83-89.

34. Watts AE, Yeager AE, Kopyov OV, Nixon AJ. Fetal derived embryonic-like stem cells improve healing in a large animal flexor tendonitis model. Stem Cell Res Ther. 2011;2:4.

35. Zhao C, Amadio PC, Paillard P, Tanaka T, Zobitz ME, Larson DR, An KN. Digital resistance and tendon strength during the first week after flexor digitorum profundus tendon repair in a canine model in vivo. J Bone Joint Surg Am. 2004;86:320-327.

36. Zhao C, Chieh H-F, Bakri K, Ikeda J, Sun Y-L, Moran SL, An $\mathrm{K}-\mathrm{N}$, Amadio PC. The effects of bone marrow stromal cell transplants on tendon healing in vitro. Med Eng Phys. 2009;31:1271-1275.

37. Zhao C, Hsu CC, Moriya T, Thoreson AR, Cha SS, Moran SL, An KN, Amadio PC. Beyond the square knot: a novel knotting technique for surgical use. J Bone Joint Surg Am. 2013;5: 1020-1027.

38. Zhao C, Sun YL, Amadio PC, Tanaka T, Ettema AM, An KN. Surface treatment of flexor tendon autografts with carbodiimidederivatized hyaluronic acid: an in vivo canine model. $J$ Bone Joint Surg Am. 2006;88:2181-2191.

39. Zhao C, Sun Y-L, Kirk RL, Thoreson AR, Jay GD, Moran SL, An $\mathrm{KN}$, Amadio PC. Effects of a lubricin-containing compound on the results of flexor tendon repair in a canine model in vivo. J Bone Joint Surg Am. 2010;92:1453-1461.

40. Zhao C, Sun YL, Jay GD, Moran SL, An KN, Amadio PC. Surface modification counteracts adverse effects associated with immobilization after flexor tendon repair. J Orthop Res. 2012;30: 1940-1944. 